\title{
SECONDARY ADRENAL INSUFFICIENCY MIMICKING ABDOMINAL CAUSE OF RECURRENT ABDOMINAL PAIN IN A PREPUBERTAL GIRL
}

\author{
Ana Milenović ${ }^{1}$, Ljiljana Šaranac ${ }^{1,2}$, Vasiliki Toli ${ }^{1}$, Dragana Ilić ${ }^{1}$, Zlatko Đurić ${ }^{1,2}$ \\ ${ }^{1}$ Pediatric Clinic, Clinical Center Niš, Serbia \\ ${ }^{2}$ University of Niš, Faculty of Medicine, Niš, Serbia
}

\begin{abstract}
Recurrent abdominal pain (RAP) in children is defined as at least three episodes of pain that occur over at least three months and affect the child's ability to perform normal activities. The prevalence of recurrent abdominal pain in a population of schoolchildren varies from $10 \%$ to even $45 \%$. Pituitary disorders are rarely considered as causative factor in children with abdominal pain, especially in absence of midline facial defects and in case of emergency, when growth monitoring is neglected or not performed carefully. Herein we report an unusual case of RAP caused by secondary adrenal insufficiency. An 8-year-old girl was hospitalized repeatedly because of RAP. Biological parameters including white blood cell count, hemoglobin value, C-reactive protein, glucose, electrolytes were within the normal range. Low cortisol combined with low ACTH values was the clue for diagnosis. The magnetic resonance imaging (MRI) of the pituitary region revealed anterior pituitary hypoplasia and pituitary stalk interruption. To the best of our knowledge, this is the first report of child with RAP caused by pituitary disorder. Possible inherited, autoimmune and post-traumatic causative factors are discussed.
\end{abstract}

Key words: recurent abdominal pain, pituitary hypoplasia, secondary adrenal insufficiency, growth hormone deficiency, hypopituitarism, pituitary stalk lesion

\section{Introduction}

Recurrent abdominal pain (RAP) in children is defined as at least three episodes of pain that occur over at least three months and affect the child's ability to perform normal activities [1]. It is one of the commonest reasons for referral to pediatrician and pediatric gastroenterologist, as well to pediatric surgeon. Almost all children have abdominal pain at one time or another. The prevalence of recurrent abdominal pain in a population of schoolchildren varies from $10 \%$ to even $45 \%[1,2]$. Mostly, it is not caused by a serious medical problem, and has transient nature. However, a vast majority of abdominal and non-abdominal causes could be involved, classified as organic or non-organic (functional, like "visceral hyperalgesia") [3). It is noteworthy to say that abdominal pain can be a sign of serious illness that seeks urgent and specific treatment. We here report an unusual case of recurrent abdominal pain accompanied by growth failure, fatigue, weakness and weight loss, caused by endocrine disorder: pituitary-adrenal axis insufficiency.
Correspondence to: Ljiljana Šaranac, Ph.D.

81 Dr. Zoran Djindjić Blvd, 18000 Niš, Serbia

Phone: +381628242161

E-mail: endoljilja@yahoo.com

Received December $23^{\text {rd }}, 2019$, Accepted January $19^{\text {th }}, 2020$

\section{Case Report}

\section{Initial examination}

In August 2018, an 8-year-old girl was referred to Pediatric Clinic of Nis because of acute abdominal pain with formed stools without hematochezia. Abdominal pain started ten days before admission. It was located in periumbilical region and was more prominent in the right iliac fossa, without vomiting and fever. Neither urinary disorders nor weight loss were documented on first admission. Her examination otherwise was normal.

She was born at term after an uneventful pregnancy; birth weight was $3.150 \mathrm{~g}$ (P25), birth length of $54.0 \mathrm{~cm}$ (P90) on Fenton growth charts. Apgar score was not available, but spontaneous breathing without cyanosis or jaundice was documented. No dysmorphic features were noticed. She was breast fed from birth until the age of 10 months when gluten was introduced into the diet without any adverse gastrointestinal effect. At the age of 3 years she experienced head injury, estimated as nonserious. Both parents were healthy and unrelated, with no history of endocrine or autoimmune diseases and with normal pubertal development.

She was proportionally short; her height of $121 \mathrm{~cm}$ was -1.88 SD (P3) for her Chronological Age (CA), her Height Age (HA) corresponded to 7 years, and her Body Mass (BM) of $22 \mathrm{~kg}$ was $0.6 \mathrm{~kg}$ below her ideal weightfor-height. Her BMI was $21.5 \mathrm{~kg} / \mathrm{m} 2$ (P27). Bone age was retarded and corresponded to 5.5 years. No signs of puberty were registered. Growth records before 8 years of age were unavailable. 
A pediatric surgeon reviewed and observed her for three days. A physical examination revealed a distended abdomen without defense or masses. Bowel sounds were present without organomegaly. An X-ray of abdomen showed only signs of constipation. The abdominal ultrasound (US) was reported as normal. Conclusion: no surgical cause of abdominal pain was discovered.

\section{First hospitalization}

An investigation of pediatric gastroenterologist was indicated. The girl was referred again to Pediatric Clinic for further investigation. Complete systemic examination showed no pathological findings. Biological parameters including white blood cell count, hemoglobin value, C-reactive protein, glucose, electrolytes were within the normal range. Stool cultures were negative. Viral tests (CMV, EBV, HSV1, and Coxsackie virus) were also negative. Furthermore, serum anti-tissue transglutaminase (tTG) antibodies (immunoglobulin IgA-tTG $=0.1 \mathrm{U} / \mathrm{mL}$, normal values $<10 \mathrm{U} / \mathrm{mL})$, ASCA $\operatorname{IgA}$ and $\operatorname{IgG}$ were negative. Fecal calprotectin test was within normal range. MSCT of abdomen and pelvis was performed and it came back normal. During hospitalization she also complained of headaches without vomiting. An examination of pediatric neurologist showed no structural causes identified of present headaches. She was treated by conservative management (rehydration and analgesia). Conclusion: no structural cause identified of abdominal pain.

The patient was discharged from the hospital with advice to use antispasmodic therapy in abdominal pain episodes.

\section{Second hospitalization}

Two weeks later, the girl was urgently admitted to Pediatric Clinic due to the worsening of symptoms. On examination, she complained of severe abdominal pain located again periumbilically and more to the right iliac fossa. A few days before admission, she was febrile to $39^{0} \mathrm{C}$. The pain occurred every day in the afternoon or early evening with vomiting. She had regular stools. Weight loss of about $3.5 \mathrm{~kg}$ was reported during more than a month. No history of polydipsia, polyuria and heat/cold intolerance was reported. She looked unwell and had clinical dehydration. Evaluation of her vital signs revealed slightly decreased blood pressure at $95 / 65 \mathrm{mmHg}$ and normal heart rate to $87 / \mathrm{min}$. Her respiratory rate was 26 breaths/min. The girl was awake and oriented but appeared weak and fatigued. Her skin turgor was reduced and capillary refill time was 2 seconds. In the right frontal part of the scalp we noticed a white scar-like linear change of $2.5 \mathrm{~cm}$ in length. The neck was supple with no goiter or adenopathy. The lungs were clear to auscultation and the heart revealed no murmurs. Bowel sounds were audible with normal genitals and no deformities in extremities were observed.
Laboratory investigations were within the normal range including electrolytes. Blood film was reported as normal. Her urine was clear on dipstick testing; urinary microscopy and culture were negative. An abdominal ultrasound (US) was requested and was reported as normal. Initially, the girl was treated by conservative management (IV rehydration with crystalloids) and analgesia. During hospitalization, she received intravenous antibiotics and corticosteroids. A pediatric surgeon was consulted and he did not find any surgical cause of the abdominal pain. This time he advised endoscopic examination. Fecal calprotectin test was positive $(1490 \mu \mathrm{g} / \mathrm{g})$, but the control calprotectin value was within normal range $(26.6 \mu \mathrm{g} / \mathrm{g})$. Upper endoscopy and colonoscopy revealed normal bowel structure. MRI enterography was performed and was reported as normal without any sign of inflammatory bowel disease (IBD). Repeatedly, the gastrointestinal causes of abdominal pain were excluded. However, the clinical picture persisted despite adequate conservative management and analgesia. It is noteworthy to say that symptoms aggravated during afternoon.

What could be the cause of recurrent abdominal pain in our patient? We considered:

- Functional abdominal pain in which no structural causes are identified in $90 \%$ of cases

- Surgical disorders;

- Gastrointestinal disorders;

- Systemic disorders;

- Renal disorders;

- Hepatobiliary/pancreatic disorders;

- Neurological/Psychosocial disorders;

- Malignant diseases;

- Endocrine disorders

- Metabolic disorders - porphyria.

Then we focused our investigation on excluding possible endocrine causes of this abdominal pain. Despite the normal blood glucose and electrolytes, the endocrinologist suggested the possibility of adrenal insufficiency and advised examination of hormonal status including TSH, FT4, PRL, cortisol and ACTH.

Extremely low levels of cortisol $(20 \mathrm{nmol} / \mathrm{l})$ and inappropriately low ACTH $(1.8 \mathrm{pg} / \mathrm{ml})$ were found, revealing secondary adrenal insufficiency (Table1). Levels of TSH, FT4, and PRL were within normal range. Repeated check of morning cortisol and ACTH level confirmed secondary adrenal insufficiency. Short ACTH stimulation test was not done because of lack of the test dose and even more because of the necessity of urgent substitution therapy.

Table 1 Confirmatory serum testing for secondary adrenal insufficiency

\begin{tabular}{lcc}
\hline Test & Patient's result & Normal value \\
\hline ACTH $(\mathrm{pg} / \mathrm{ml})$ & $1.8 \mathrm{pg} / \mathrm{ml}$ & $(7.20-63.30)$ \\
Cortisol $(\mathrm{nmol} / \mathrm{l})$ & $20.0 \mathrm{nmol} / \mathrm{l}$ & $(166.0-507.0)$ \\
Cortisol in ACTH & Non available & $>550$ \\
stimulation test & & \\
\hline
\end{tabular}


The magnetic resonance imaging (MRI) of the pituitary region showed the anterior pituitary hypoplasia and pituitary stalk interruption (Fig. 1 and Fig. 2). We concluded that the cause of adrenal insufficiency in this case is of pituitary origin: pituitary hypoplasia (congenital or acquired) which resulted in partial hypopituitarism, presenting as RAP caused by secondary adrenal insufficiency.

The patient's abdominal symptoms resolved immediately after introduction of the first doses of substitution therapy with higher physiological doses of hydrocortisone. Hydrocortisone is given in 3 separate doses with a typical total daily dose of $15 \mathrm{mg} / \mathrm{m}^{2} ; 7.5 \mathrm{mg}$, in the morning, $2.5 \mathrm{mg}$ at lunchtime and early evening (6:00PM). During acute febrile illness or in case of trauma, the parents were advised to double the hydro-

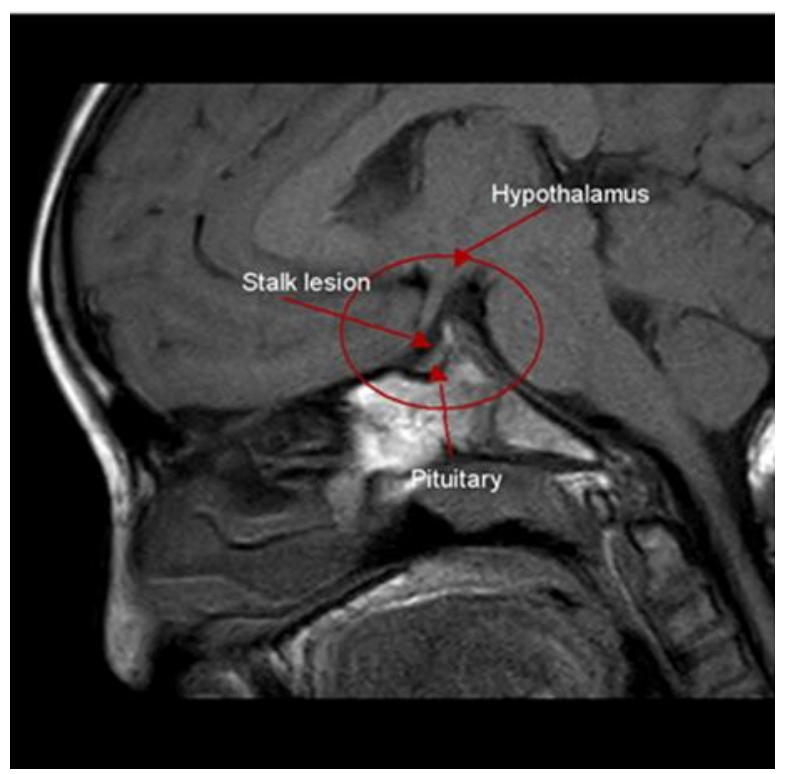

Fig. 1 Sagittal pituitary MRI showing pituitary hypoplasia

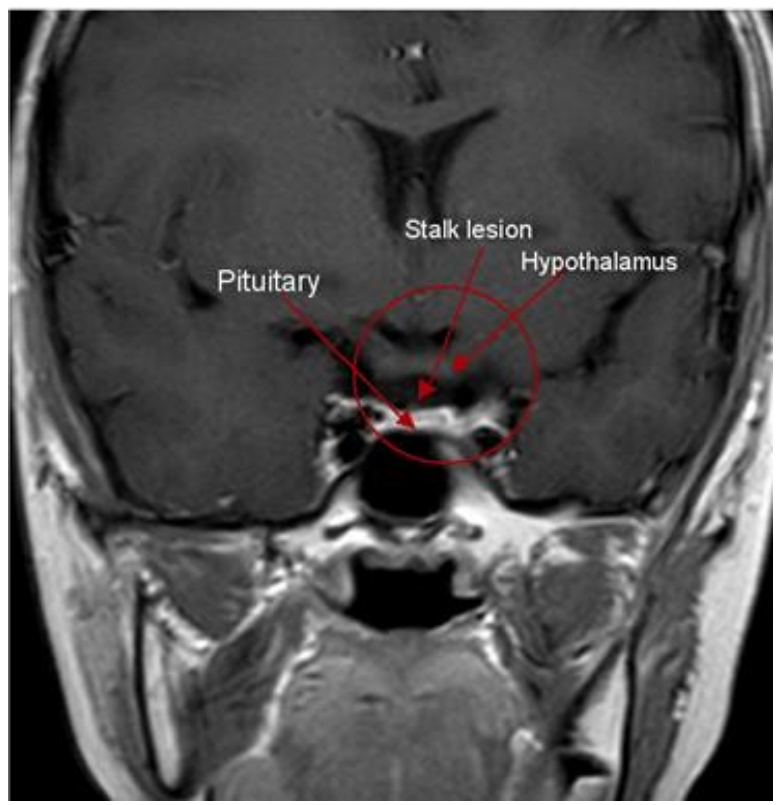

Fig. 2 Coronal pituitary MRI cortisone dose. In case of vomiting and diarrhea, the advice was to triple the daily dose. In the later occasion, it would be necessary to give intravenous hydrocortisone and crystalloids [4].

\section{Evaluation of the treatment effect}

Two weeks later, the girl was admitted for evaluation of the replacement therapy quality. Her abdominal symptoms resolved with implementation of hydrocortisone, but the fatigue persisted. Hypotension and headache were still reported.

Control hormonal status showed still low values of morning cortisol and ACTH, low levels of PRL and euthyroid state. The patient's gonadotropin levels corresponded to prepubertal values. Hydrocortisone therapy was corrected and increased to a total daily dose of $18 \mathrm{mg} / \mathrm{m}^{2}$ : $10 \mathrm{mg}$ in early morning, $5 \mathrm{mg}$ at lunchtime and $2.5 \mathrm{mg}$ at early evening (6:00 PM), with advice of dose adjustment as above.

Since the patient's height of $120.5 \mathrm{~cm}$ has been on P3 for her Chronological Age (CA) in discordance with MPH (Mean Predicted Height calculated being on P75) and the fact that some complaints could be attributed to growth hormone deficiency (GHD), recombinant growth hormone was introduced without previous testing of somatotropic axis. We made this decision based on documented structural pituitary stalk lesion and anterior pituitary hypoplasia. IGF1 determination was not available. Growth hormone deficiency was assumed as certain and under such circumstances GH stimulation tests are unnecessary, and even dangerous [5-11]. Introduction of GH therapy led to complete patient's recovery. Further follow-up and growth will eventually unmask other pituitary deficiencies.

\section{Discussion}

Pituitary disorders are rarely considered as a causative factor in children with abdominal pain, especially in absence of midline facial defects and in cases of emergency, when growth monitoring is neglected or not performed carefully. In our experience, pediatric gastroenterologists do care about neighboring organ status (testis torsion or basal pneumonia), but with the exception of DKA (Diabetic Ketoacidosis) or CAH (Congenital Adrenal Hyperplasia), they do not consider any other endocrine cause of abdominal pain (hypopituitarism, pheochromocytoma or hyperparathyreodismus i.e.). Herein we reported an unusual case of RAP caused by secondary adrenal insufficiency. Low cortisol combined with low ACTH values was of diagnostic value. Pituitary morphology investigation revealed structural abnormality of pituitary and pituitary stalk: anterior pituitary hypoplasia and pituitary stalk interruption (Fig. 1 and Fig. 2). Posterior pituitary was in situ with normal "bright reflex" on MRI (Fig. 1). 
Adrenal insufficiency may result from a wide variety of congenital and acquired disorders of adrenal cortex, pituitary and hypothalamus (Table 2), adapted from Sasigarn and Rohan [12]. Destruction or dysfunction of the adrenal cortex is the cause of primary adrenal insufficiency (PAI) and its initial clinical presentation or relapse is frank and well known as "adrenal crisis" (AC), a medical emergency presenting as vomiting and abdominal complaints imitating gastrointestinal cause of dehydration. The progression could be gradual and nonspecific from hypotension to shock, depending on the degree of insufficiency and precipitating stress events. The electrolyte profile is typical; hyponatremia, hypochloremia, hyperkalemia (usually in PAI) and hypoglycemia (in children) accompanied by metabolic acidosis and occasionally hypercalcemia . However, it is very often misdiagnosed despite of well-established diagnostic criteria [13-18]. In contrast, electrolytes in secondary adrenal insufficiency (SAI) are usually within normal range. The hypoadrenalism is therefore due to pituitary or hypothalamic disorder, resulting in absence of the normal ACTH stimulation to the adrenal cortex. The consequence is partial or total cortisol deficiency but often a normal or near normal production of aldosterone. Mineralocorticoid secretion is not impaired because of primary regulation of aldosterone synthesis by the renin-angiotensin system among other stimuli. That is why it is more hidden and difficult to recognize. Cortisol provides some $30-50 \%$ of normal mineralocorticoid activity as it is present in great excess to aldosterone. The clinical symptoms of secondary adrenal insufficiency are also related to the degree of cortisol deficiency. The most common signs and symptoms are dry skin, decreased pubic/axillary hair, myalgia, arthralgia, severe fatigue, abdominal pain, loss of appetite, weight loss, nausea, vomiting, diarrhea, muscle weakness, headache, irritability, and depression or decreased consciousness. Since aldosterone is typically not diminished, low blood pressure and muscle spasms are not so prominent and severe as they are in primary adrenal insufficiency. Unlike in Addison's disease, hyperpigmentation does not occur $[12,15]$.
Pituitary stalk lesions (PSL) in children depicted on MRI investigation are rarely reported. There are only few clinical series published recently [19-21]. Secondary adrenal insufficiency was the least common condition and, when present, was always associated with deficiency of at least one other axis [19]. In our patient, documented secondary adrenal insufficiency and "certain"GH deficiency could be acquired as consequence of acute posttraumatic hypopituitarism (MRI of the pituitary region showed pituitary stalk interruption). Also, hypopituitarism could be congenital taking into account the MRI finding of the pituitary hypoplasia. Hamilton an al examined the causes of pituitary stalk lesions in adults and children. They noted that in adults inflammatory lesions were most common, while in children congenital lesions predominated [22]. Although, the MRI of the pituitary region in our patient showed only pituitary hypoplasia and pituitary stalk interruption, there were no criteria for Pituitary stalk interruption syndrome (PSIS). PSIS is characterized by MRI finding of a thin or absent pituitary stalk, associated hypoplastic or aplastic anterior pituitary and ectopic posterior pituitary (EPP). Clinically, PSIS can be associated with midline defects and various pituitary endocrine deficiencies, ranging from isolated growth hormone deficiency (IGHD) to combined pituitary hormone deficiency (CPHD). The endocrine outcome seems to be a progressive onset of hormone deficiencies leading to panhypopituitarism, but posterior pituitary function is usually maintained [22, 23].

The clinical presentation of posttraumatic stalk lesion can be similar as in PSIS [24]. Our patient does not fulfill MRI criteria for PSIS, since no ectopic posterior pituitary was found. It was challenging to find the cause of hypopituitarism; congenital pituitary hypoplasia due to genetic mutation, posttraumatic stalk lesion, lymphocytic hypophysitis or all together. Unfortunately, genetic analysis was not available, as well as pituitary antibodies determination [25]. The patient did have a history of the head injury. The hormonal axis most often chronically affected in patients with traumatic hypopituitarism

Table 2 Causes of adrenal insufficiency

\begin{tabular}{|c|c|}
\hline Primary Adrenal Insufficiency (PAI) & Secondary or Central Adrenal Insufficiency (SAI) \\
\hline 1.Congenital adrenal hyperplasia $(\mathrm{CAH})$ & I congenital causes \\
\hline 2.Bilateral adrenal hemorrhage of the newborn & $\begin{array}{l}\text { 1. Septo-optic dysplasia } \\
\text { (SOD), HESX1, SOX2, SOX3, OTX2 }\end{array}$ \\
\hline $\begin{array}{l}\text { 3. Adrenal hemorrhage of acute infection } \\
\text { (Waterhouse-Friderichsen syndrome) }\end{array}$ & $\begin{array}{l}\text { 2. Pituitary aplasia, pituitary hypoplasia } \\
\text { (LHX3, LHX4, OTX2, PROP1) }\end{array}$ \\
\hline $\begin{array}{l}\text { 4. Autoimmune adrenalitis (isolated or part of autoimmune } \\
\text { polyglandular syndrome type } 1 \text { and } 2 \text { ) }\end{array}$ & $\begin{array}{l}\text { 3. Mutations in gene of POMC } \\
\text { (Pro-opiomelanocortin) }\end{array}$ \\
\hline $\begin{array}{l}\text { 5.Infection (e.g. tuberculosis, fungal infection, } \\
\text { human immunodeficiency virus, cytomegalovirus) }\end{array}$ & II acquired SAI \\
\hline $\begin{array}{l}\text { 6. Triple A syndrome or Allgrove syndrome } \\
\text { (alacrimia, achalasia, adrenal insufficiency) }\end{array}$ & 1. Trauma \\
\hline 7.Adrenal unresponsiveness to ACTH due to gene mutations & 2. Brain tumors \\
\hline $\begin{array}{l}\text { 8.Drug effects (mitotane, ketoconazole, } \\
\text { aminoglutethimide, metyrapone, megestrol, rifampin) }\end{array}$ & $\begin{array}{l}\text { 3. Iatrogenic causes: surgery, cranial irradiation, steroid } \\
\text { withdrawal after prolonged administration }\end{array}$ \\
\hline
\end{tabular}


is the growth hormone axis. In the acute phase following traumatic brain injury, the hormonal axes most often affected are the gonadotropin axis $(41.6 \%)$, the growth hormone axis $(20.4 \%)$, the ACTH axis $(9.8 \%)$, and the thyroid axis $(5.8 \%)$. ACTH production is usually a late function to be lost in pituitary disease and is therefore almost always associated with gonadotropin and $\mathrm{GH}$ deficiency. Hormonal dysfunction tends to be at least partially improved in up to $60 \%$ of patients following a traumatic injury [26]. Detection of pituitary antibodies has been used to aid in the diagnosis of post traumatic hypopituitarism [25].

A genetic cause was also considered in our patient but couldn't be confirmed. We did not have possibilities to investigate numerous genes encoding transcriptional factors, identified as critical for pituitary development during early embryonic life. Identified responsible genes for CPHD that includes ACTH deficiency, are numerous: HESX1, LHX3, LHX4, OTX2, PROP1 [10, 27-29]. Complex interplay between congenital and environmental factors with the influence of endogenous factors may result in pituitary malformation. It appears that pituitary talks back to hypothalamus, so that connections between them are vital for normal development of both structures.

To the best of our knowledge, this is the first report of a child with RAP caused by pituitary disorder. We documented the hormonal dysfunction and dysmorphic

\section{References}

1. Apley J, Naish N. Recurrent abdominal pains: a field survey of 1000 school children. Arch Dis Child 1958; 33:165-170.

2. Kokkonen J, Haapalahti M, Tikkanen S, Karttunene R, Savilahtl E.Gastrointestinal complaints and diagnosis in children: a population basedstudy. Acta Pediatr 2004; 93:880-886.

3. Di Lorenzo C, Youssef NN, Sigurdsson L, Scharff L, Griffiths J, Wald A. Visceral hyperalgesia in children with functional abdominal pain. J Pediatr 2001; 139:838-843.

4. Butler G, Kirk J. Endocrine Emergencies. In: Pediatric Endocrinology and Diabetes. New York: Oxford University Press Ed; 2011. p. 303-328.

5. Growth Hormone Research Society; GH Research Society. Consensus guidelines for the diagnosis and treatment of growth hormone $(\mathrm{GH})$ deficiency in childhood and adolescence: summary statement of the GH Research Society. J Clin Endocrinol Metab 2000; 85:3990-3993.

6. Fraiser D. Editorial: the treatment of childhood and adolescent growth hormone deficiency-consensus or confusion?J Clin Endocrinol Metab 2000; 85:3988-3989.

7. Gandrud LM, Wilson DM. Is growth hormone stimulation testing in children still appropriate? Growth Horm \& IGF Res 2014; 14:185-194.

8. Pampanini V, Pedicelli S, Gubinelli J, Scire G, Cappa M, Boscherini $\mathrm{B}$ et al. Brain magnetic resonance imaging as firstline investigation for growth hormone deficiency diagnosis in early childhood. Horm Res Paediatr 2015; 84:323-330.

9. Grimberg A, DiVall SA, Polichronakos C, Allen DB, Cohen IE, Quintos JB et al. Guidelines for growth hormone and insulinlike growth factor-I treatment in children and adolescents: growth hormone deficiency, idiopathic short stature, and primary insulin-like growth factor deficiency. Horm Res Padiatr 2016; 86:361-397.

10. Alatzoglou KS, Webb EA, Tissier Pl, Dattani M. Isolated growth hormone deficiency (GHD) in childhood and adolescence. Endocrine Rev 2014; 35:376-432. pituitary. The nature of the SAI in this case, congenital or acquired, remains to be fully elucidated. Secondary adrenal insufficiency usually presents as vague clinical symptoms with the wide range of clinical signs making it difficult to diagnose. Timely recognition and clinical management of adrenal insufficiency are critical to prevent morbidity and mortality.

\section{Conclusion}

Adrenal insufficiency of pituitary origin was the cause of RAP in an 8-year-old girl mimicking the abdominal cause of disease. The diagnosis was late and child's suffering was prolonged with possibility of negative outcome. We concluded that the first and more prominent complaint of central adrenal insufficiency in childhood could be RAP, so immediate endocrine evaluation is mandatory. Pituitary insufficiency may evolve over time and children must be kept under careful endocrine follow-up. Untreated hormonal abnormalities could lead to life-threatening AC.

Acknowledgments: Supported by grants from the Ministry of Education, Science and Technological Development of Republic of Serbia No 31060, No 41018 and Internal Project No 37 of Faculty of Medicine Nis, University of Nis, Serbia.

11. Saranac L. The unbearable lightness of prescribing growth hormone. Facta Univ Ser Med Biol 2018; 20(2): 35-39.

12. Sasigarn BA, Rohan H. Pediatric adrenal insufficiency: diagnosis, management and new therapies (Review). International Journal of Pediatrics 2018; (1):1-8. https://doi.org/10.1155/2018/1739831

13. Chaudhuri S. Rao KN, Ommurugan B, Varghese G. Addison's disease mimicking acute pancreatitis. J Clin Diagn Res 2017; 11:12-13

14. Tritos NA. Adrenal Hemorrhage. In: Adrenal Hemorrhage. New York, NY: WebMD. http://emedicine.medscape.com/article/ 126806. Updated March 3, 2017. Accessed March 13, 2017.

15. Charmandari E, Nicolaides NC, Chrousos GP. Adrenal insufficiency. Lancet. 2014; 383(9935): pp. 2152-2167. doi: 10.1016/s0140-6736(13)61684-0.

16. Nieman LK. Clinical manifestations of adrenal insufficiency in adults. In: Post TW, ed. UpToDate. Waltham, MA: UpToDate. https://www.uptodate.com/contents/clinical-manifestations-ofadrenal-insufficiency-in-adults. Last updated November 4, 2016. Accessed February 19, 2017.

17. Bornstein SR, Allolio B, Arlt W, et al. Diagnosis and Treatment of Primary Adrenal Insufficiency: An Endocrine Society Clinical Practice Guideline. J Clin Endocrinol Metab. 2016; 101(2): pp. 364-389. doi: 10.1210/jc.2015-1710.

18. Shulman DI, Palmert MR, Kemp SF. Adrenal insufficiency: still a cause of morbidity and death in childhood. Pediatrics. 2007; 119(2):e484-e494. doi: 10.1542/peds.2006-1612.

19. Turcu AF, Erickson BJ, Lin E, Guadalix S, Schwartz K, Scheithauer BW et al. Pituitary stalk lesions: the Mayo clinic experience. J Clin Endocrinol Metab 2013; 98:1812-1818.

20. Grossman AB. Clinical review: the diagnosis and management of central hypoadrenalism. J Clin Endocrinol Metab. 2010; 95(11):4855-4863. doi: 10.1210/jc.2010-0982.

21. Doknic M, Milijic D, Pekic S, Stojanovic M, Savic D, Manojlovic-Gacic E et al. Single center study of 53 consecutive 
patients with pituitary stalk lesions. Pituitary 2018; 21(6):605614. https://doi.org/10.1007/s11102-018-0914-2

22. Hamilton BE, Salzman KL, Osborn AG. Anatomic and pathologic spectrum of pituitary infundibulum lesions. AJR Am J Roentgenol 2007; 188:W223-W232.

23. Gutch M, Kumar S, Mohd Razi S, Saran S, Kumar Gupta K. Pituitary stalk interruption syndrome: case report of three cases with review of literature. J Pediatr Neurosci 2014; 9:188-191

24. Ruszala A, Wojcik M, Krystynowicz A, Wyrobek L, Starzyk JB. Post-traumatic hypopituitarism caused by pituitary stalk transection. 57 Annual ESPE Meeting 2018, Athens 27-29 Sep: P3-286.
25. De Graff L, De Bellis A, Bellastella A, Hokken Koelega. Antipituitary antibodies in Dutch patients with idiopathic hypopituitarism. Horm Res 2009; 71:22-27.

26. Fernandez-Rodriguez A, Bernabeu I, Isabel Castro A, Kelestimur F, Casaneuva FF. Hypopituitarism folowing traumatic brain injury: determining factors for diagnosis. Front Endocrinol (Lausanne). 2011; 2:25. . doi:10.3389/fendo.2011.00025

27. Kelberman D, Dattani MT. Septo-Optic dysplasia-novel isights into aetiology. Horm Res 2008; 69:257-265

28. Saranac L, Gucev Z. New insights in septo-optic dysplasia. Prilozi 2014; 35:123-128.

29. Saranac L, Bjelakovic B, Djordjevic D, Novak M, Stankovic T. Hypopituitarism occurring in neonatal sepsis. J Pediatr Endocrinol Metab 2012; 25:847-848. 